\title{
Effect of chitosan membrane surface modification via plasma induced polymerization on the adhesion of osteoblast-like cells $\dagger$
}

\author{
Paula M. López-Pérez, ${ }^{* a b}$ Alexandra P. Marques, ${ }^{a b}$ Ricardo M. P. da Silva, ${ }^{a b}$ Iva Pashkuleva ${ }^{a b}$ and \\ Rui L. Reis*ab
}

Received 15th May 2007, Accepted 3rd August 2007

First published as an Advance Article on the web 21st August 2007

DOI: $10.1039 / \mathrm{b} 707326 \mathrm{~g}$

The surface of solvent cast chitosan membranes was modified using a two-step procedure. Oxygen plasma treatment was used at the first activation step followed by vinyl monomer graft polymerization. Two monomers were used in order to compare the influence of different functional groups on cell adhesion and proliferation; acrylic acid (AA) was used to introduce carboxyl groups and vinyl sulfonic acid (VSA) was used as a source of sulfonic groups. The surface chemistry/energy changes were characterized by means of X-ray photoelectron spectroscopy (XPS), Fourier transform infrared spectroscopy (FTIR-ATR), and contact angle measurements. Additionally, alterations in the surface morphology were investigated by scanning electron microscopy (SEM). XPS analyses confirmed the polymer grafting on the surface; an $\mathrm{S}_{2 \mathrm{~s}}$ peak appears in the VSA survey spectrum and an $\mathrm{O}-\mathrm{C}=\mathrm{O}$ peak emerges in the $\mathrm{C}_{1 \mathrm{~s}}$ high resolution spectrum after AA grafting. Moreover, contact angle measurements showed an increment in the values of the surface energy polar and Lewis base components for all treated samples, confirming the introduction of additional polar groups by the modification processes. FTIR-ATR spectra showed no significant difference between treated and original materials. These results confirmed that only the very top (a few angstroms) surface layer, but not the bulk of the material, was modified. The effect of modification on the adhesion and proliferation of osteoblast-like cells was studied on a preliminary basis. Direct contact tests were performed using a human osteosarcoma cell line (SaOs-2). Cell morphology (optical microscopy and SEM) and cell viability (MTS test) were evaluated for untreated and surface modified membranes. The results revealed that both plasma treatment, and the presence of sulfonic groups on the surface of chitosan membranes, improve SaOs-2 adhesion and proliferation when compared to untreated or AA-grafted membranes. This effect was strongly related to the polar and Lewis basic components of the total surface energy.

\section{Introduction}

Chitin, derived from the exoskeletons of crustaceans and insects, is the second most abundant polysaccharide in nature next to cellulose. Chitosan is a copolymer composed of $N$-acetyl-D-glucosamine (GlcNAc) and D-glucosamine $(\mathrm{GlcN})$ units linked by $\beta$-D $(1 \rightarrow 4)$ bonds, and it is obtained by partial $N$-deacetylation of chitin. In fact, the term chitosan refers to a series of deacetylated chitins with different molecular weight (50 kD to $2000 \mathrm{kD})$, viscosity, and degree of $N$-deacetylation (40 to $98 \%$ ). ${ }^{1}$

Due to its special properties, namely biocompatibility, biodegradability and non-toxicity, ${ }^{2}$ this natural polymer has been proposed for a number of applications in the biomedical field such as wound dressings, drug delivery or skin regeneration. ${ }^{2,3}$

a3B's Research Group - Biomaterials, Biodegradables and Biomimetics, Dept. of Polymer Engineering, University of Minho, Campus de Gualtar, 4710-057Braga, Portugal.E-mail: plopez@dep.uminho.pt (Paula M. López-Pérez);rgreis@dep.uminho.pt (Rui L.Reis)

${ }^{b} I B B$ - Institute for Biotechnology and Bioengineering, PT Government Associated Laboratory, Braga, Portugal

$\uparrow$ This paper is part of a Journal of Materials Chemistry theme issue on biomedical materials. Guest editor: Cameron Alexander.
The $\mathrm{pH}$-dependent solubility of chitosan offers a suitable membrane-processing route under mild conditions. ${ }^{4}$ However, it was found that native chitosan membranes do not support cell adhesion and proliferation. .,6 $^{2}$

The surface is the first point of contact between the living body and the biomaterial when a certain device is implanted into the body. It is well known ${ }^{7}$ that the surface properties of biomaterials, namely chemistry, topography and/or surface energy, are essential factors for cell adhesion and proliferation and consequently for the performance (rejection or acceptance) of a potential device. Therefore, adequate surface modification of chitosan membranes can improve their biocompatibility in terms of better cell adhesion and proliferation without changing the key physical properties of chitosan itself. The alteration of the presence and density of polar groups on the material's surface can be used to tailor its wettability and surface free energy ${ }^{8-10}$ and hence to adjust surface biocompatibility in accordance with the application. Furthermore, the introduced polar groups can be used for the immobilisation of bioactive molecules or to control protein adsorption on the surface. ${ }^{11}$

In the medical field, surface modifications resulting in very thin layers with a thickness of ten to one hundred nanometres 
are considered to be suitable. ${ }^{12}$ Several methods have been used to render biomaterials with appropriate surface properties. Among them, plasma-surface modification is an effective and economical technique, applicable for many materials and of growing interest in the biomaterials field. The main advantage of plasma modification techniques is that the surface properties can be enhanced selectively, while the bulk attributes of the materials remain unchanged. Plasma based treatments have been largely used for medical applications with different aims, such as the introduction of new functionalities, enhancement of surface wettability, increase of the surface oxygen concentration and improvement of the interfacial adhesion. ${ }^{13}$

This work reports a graft polymerization of acrylic and vinylsulfonic polar monomers on the surface of chitosan membranes preactivated by oxygen plasma treatment. The effects of the plasma treatment itself, as well as of the different functional groups introduced by the subsequent surface grafting polymerization, on the osteoblast like cell behaviour (adhesion and proliferation) are also reported.

\section{Materials and methods}

Chitosan (CHT), purchased from Sigma-Aldrich, was purified as follows. Chitosan was dissolved at a concentration of $1 \%(\mathrm{w} / \mathrm{v})$ in $1 \%$ acetic acid $(\mathrm{AcOH})$ aqueous solution. The solution was filtered and re-precipitated with a slight excess of sodium hydroxide $(\mathrm{NaOH})$ solution, until a sudden decrease in the viscosity of the solution was observed, corresponding to the equivalent point. The product was thoroughly washed with water until a stable $\mathrm{pH}$ was reached. The obtained precipitate was washed with ethanol and freeze-dried. Acrylic acid (AA, Merck) and vinyl sulfonic acid, sodium salt (VSA, Aldrich) were used without further purification.

The chitosan degree of deacetylation (DD) was determined by ${ }^{1} \mathrm{H}$-NMR using the method proposed by Hirai et al. ${ }^{14}$ The molecular weight $(\mathrm{Mv})$ was determined by viscometry using a $0.5 \mathrm{M} \mathrm{AcOH}-0.2 \mathrm{M} \mathrm{NaOAc}$ aqueous solution as solvent. The measurements were performed at $25{ }^{\circ} \mathrm{C}$. The Mark-Houwink parameters determined by Terbojevich et al. ${ }^{15}$ were used for the calculations. The obtained values for the DD and Mv were 93\% and $790 \mathrm{kDa}$, respectively.

\section{Membrane preparation}

Chitosan films (thickness approx. $50 \mu \mathrm{m}$ ) were prepared by solvent casting. Purified chitosan powder was dissolved in aqueous AcOH 1\% (v/v) solution at a concentration of $1 \% \mathrm{wt}$. The solution was carefully stirred to avoid air bubble formation, cast into Petri dishes $\left(0.5 \mathrm{~g} \mathrm{~cm}^{-2}\right)$ and dried at room temperature. The obtained membranes were neutralized by immersion in a $0.1 \mathrm{M} \mathrm{NaOH}$ solution, washed with water and dried at room temperature.

\section{Surface modification}

Plasma treatment was applied to activate the surface of the chitosan films by free radical formation. These radicals were expected to initiate further graft copolymerization of vinyl monomers. The plasma treatment was performed using radio frequency (13.56 MHz) Plasma Prep5 equipment from Gala Instruments. Samples were exposed to $\mathrm{O}_{2}$ plasma at $30 \mathrm{~W}$ of power for 15 minutes. The pressure in the reactor was maintained around $20 \mathrm{~Pa}$ by regulating the gas flow. Subsequently, the activated samples were immersed in a degassed $10 \% \mathrm{wt}$ monomer solution (solvents: 2-propanol for AA and acetone for VSA grafting) and kept at room temperature for $2 \mathrm{~h}$. The $\mathrm{pH}$ of the AA solution was adjusted $(\mathrm{pH}=5)$ by triethylamine. In order to remove the nongrafted monomer, samples were washed thoroughly with a suitable solvent (2-propanol for AA and water for VSA grafted membranes).

\section{X-Ray photoelectron spectroscopy (XPS)}

XPS was used to characterise the surface chemistry of treated and untreated samples. The XPS analyses were performed using a VG Escalab 250 iXL ESCA instrument from VG Scientific. Monochromatic Al-K $\alpha$ radiation $(h v=1486.92 \mathrm{eV})$ and a take off angle of $90^{\circ}$ relative to the sample surface were used. The measurements were carried out in a Constant Analyser Energy mode (CAE) with $100 \mathrm{eV}$ pass energy for survey spectra and $20 \mathrm{eV}$ pass energy for high resolution spectra. Charge referencing was adjusted by setting the lower binding energy hydrocarbon $\mathrm{C}_{1 \mathrm{~s}}$ peak at $285.0 \mathrm{eV}$. Overlapping peaks were resolved into their individual components by XPSPEAK 4.1 software.

\section{Fourier-transform infrared spectroscopy (FTIR)}

The surface chemical analysis was also performed by FTIR spectroscopy using an IRPrestige 21 FTIR spectrophotometer with an attenuated total reflectance (ATR) device from Shimadzu. Spectra were taken with a resolution of $4 \mathrm{~cm}^{-1}$ and averaged over 36 scans.

\section{Scanning electron microscopy (SEM)}

The surface morphology changes were observed using S360 SEM Equipment from Leica Cambridge, UK. Prior to SEM examination, a conductive thin gold film was deposited on the sample surface by a Sputter Jeol JFC 1000.

\section{Contact angle measurements}

Changes of the surface wettability and the surface free energy for the modified surfaces were evaluated by contact angle measurements. Static contact angle measurements were carried out by the sessile drop method using a contact angle meter OCA $15+$ with high-performance image processing system from DataPhysics Instruments. A drop $(1 \mu \mathrm{L})$ of the used liquids (methylene iodide, glycerol or formamide) was added by a motor driving syringe at room temperature. Two different samples of each material were used and at least three measurements were carried out for each sample. The presented data correspond to the final average value. The surface energy and its components (polar and dispersive) were calculated by means of the Owens, Wendt, Rabel and Kaelble (OWRK) method, ${ }^{16}$ using the contact angle values obtained both for glycerol and methylene iodide.

Additionally, the Lewis acid and basic contributions to the surface energy were calculated using the acid-base method 
(AB method). This method based on the Van Oss-ChauduryGood theory allowed determination of the ion pair acceptor and ion pair donor behaviour of the studied surfaces. The $A B$ method requires at least a three liquid system from which two should be polar and one non-polar. Glycerol and formamide were used as polar liquids and methylene iodide was employed as the non-polar one. Contact angle measurements were also performed using water, but the values were not included in the calculations of the surface free energy, because such values lack physical meaning, as discussed below.

\section{Cell culture}

Direct contact assays were performed in order to evaluate the effect of the applied surface treatments on cell adhesion and proliferation. A human osteosarcoma cell line (SaOs-2), an immortalized cell line with an osteoblastic phenotype, was obtained from the European Collection of Cell Cultures (ECACC, UK) and was used in the cell culture studies. The cells were cultured in Dulbecco's modified Eagle's medium (DMEM; Sigma-Aldrich, Inc, USA) supplemented with $10000 \mathrm{U} \mathrm{ml}^{-1}$ penicillin-G sodium, $10000 \mathrm{\mu g} \mathrm{ml}^{-1}$ streptomycin sulfate and $25 \mu \mathrm{g} \mathrm{ml}^{-1}$ amphotericin B in a $0.85 \%$ saline (Gibco, Invitrogen Corporation, UK) and $10 \%$ of heatinactivated fetal bovine serum (FBS; Biochrom AG, Germany) in a humidified atmosphere with $5 \%$ of $\mathrm{CO}_{2}$. Cells were seeded onto the materials at a concentration of $3 \times 10^{4}$ cells $/ \mathrm{ml}$, $1 \mathrm{ml}$ per well and incubated for 1,3 and 7 days.

Prior to culturing, all samples were sterilized with ethylene oxide $\left(\right.$ EtO) under the conditions previously described. ${ }^{17}$

\section{Cell morphology}

Cell morphology was observed by SEM and optical microscopy at each time point. The cultured materials were washed with $0.1 \mathrm{M}$ phosphate buffered saline solution (PBS, Sigma Chemical Co., USA) and then fixed with $2.5 \%$ glutaraldehyde (BDH, UK) solution in PBS for 30 min at room temperature. Once again, the membranes were washed and kept in PBS at $4{ }^{\circ} \mathrm{C}$ until being stained or prepared for SEM observation. When optical microscopy was used for observation, the surface of the materials was stained with $0.4 \%$ methylene blue solution in water and examined in an Axioplan Imager Z1 from Zeiss, Germany. The samples, subjected to SEM observation, were first dehydrated by gradient ethanol concentrations. Complete drying was achieved by using hexamethyldisilazane (HMDS; Electron Microscopy Sciences, USA) to substitute critical point drying equipment. After overnight drying, samples were coated by sputtering of gold and observed by SEM.

\section{MTS assay}

Cell viability was quantified by MTS assays. The assays were performed after 1,3 and 7 days. The cultured materials were washed with $0.1 \mathrm{M}$ phosphate buffered saline solution (PBS, Sigma Chemical Co., USA) and then treated with $500 \mu$ of MTS solution in DMEM culture medium without phenol red (Sigma-Aldrich, Inc, USA). The cell culture plates were incubated for 3 hours at $37^{\circ} \mathrm{C}$ in a humidified atmosphere of $5 \% \mathrm{CO}_{2}$. Optical Density (OD) was read in a microplate reader
(Bio-Tek, USA) at $490 \mathrm{~nm}$. The reported data are averaged over two sets of assays. Four replicates of each material per set were used.

\section{Results and discussion}

Tailoring material surface properties is of great importance especially for biomedical materials in direct contact with the body environment. Changes in surface chemistry/topography may enhance cell adhesion and proliferation leading to an improvement of the material biocompatibility. The hypothesis tested in this study is that alterations in the surface polarity of chitosan membranes by simple $\mathrm{O}_{2}$ plasma treatment, or by plasma activation and subsequent grafting of monomers with ionisable, hydrophilic groups, will lead to significant changes in cell behaviour. The ultimate aim of this study is to get some insight into general trends leading to better materials biocompatibility concerning their interactions with biological systems (proteins, cells, etc).

\section{XPS analysis}

XPS analysis was carried out to determine the surface chemical composition of modified and non-modified materials. As expected, three main elements: carbon, oxygen and nitrogen were present in the survey spectrum of chitosan membranes. Silicon was also detected for all samples at a concentration of around $3 \mathrm{at} \%$. The chitosan used in this study is produced from crab shells and it seems that the manufacturing and purification methods can not remove all the silicon. Other elements $(\mathrm{Cl}, \mathrm{Ca}, \mathrm{Al}, \mathrm{Mo}$ and $\mathrm{Sn})$ appear in the composition of some samples, normally in very small concentrations (less than $0.5 \mathrm{at} \%$ ), and were excluded from the elemental analysis (at $\%$ ) shown in Table 1.

Modification by oxygen plasma only resulted in higher oxygen content for the treated samples compared to the untreated ones. When vinyl sulfonic acid was grafted onto the activated surfaces, a characteristic signal corresponding to Sulfur $\left(\mathrm{S}_{2 \mathrm{~s}}\right)$ was present in the survey spectrum of the modified samples. The $\mathrm{S}_{2 \mathrm{~s}}$ transition was used to quantify this element, because the most intense and quantitative signal for sulfur $\left(\mathrm{S}_{2 \mathrm{p}}\right.$ ) was overlapped with the $\mathrm{Si}_{2 \mathrm{~s}}$ (loss) peak.

Fig. 1 shows the $C_{1 s}$ high-resolution spectra of the studied materials. The respective data are summarized in Table 2. The $\mathrm{C}_{1 \mathrm{~s}}$ core level spectrum of chitosan membranes reveals four peaks. The $285.0 \mathrm{eV}$ peak was assigned to $C-\mathrm{H}$ and $C-\mathrm{C}$ bonds in the chitosan backbone. The peak at $285.57 \mathrm{eV}$ corresponds to $C-\mathrm{NH}_{2}$ from glucosamine rings. The peak present at $286.71 \mathrm{eV}$ was assigned to $C-\mathrm{O}, C-\mathrm{OH}$ and $C-\mathrm{N}-\mathrm{C}=\mathrm{O}$ and the peak at $288.18 \mathrm{eV}$ to $\mathrm{O}-C-\mathrm{O}$ and $\mathrm{N}-C=\mathrm{O}$ chemical binding.

Table 1 Chemical composition of untreated and modified materials determined by XPS

\begin{tabular}{lcccccc}
\hline Material & $\begin{array}{l}\mathrm{C}_{1 \mathrm{~s}} \\
(\%)\end{array}$ & $\begin{array}{l}\mathrm{O}_{1 \mathrm{~s}} \\
(\%)\end{array}$ & $\begin{array}{l}\mathrm{N}_{1 \mathrm{~s}} \\
(\%)\end{array}$ & $\begin{array}{l}\mathrm{S}_{2 \mathrm{~s}} \\
(\%)\end{array}$ & $\begin{array}{l}\mathrm{Si}_{1 \mathrm{~s}} \\
(\%)\end{array}$ & $\begin{array}{l}\mathrm{O}: \mathrm{C} \\
\text { ratio }\end{array}$ \\
\hline Chitosan & 71.5 & 21.8 & 3.4 & - & 3.4 & $0.30: 1$ \\
Plasma $\mathrm{O}_{2}$ & 65.0 & 24.4 & 8.2 & - & 2.3 & $0.38: 1$ \\
AA grafting & 74.1 & 19.6 & 2.9 & - & 3.3 & $0.26: 1$ \\
VSA grafting & 70.2 & 22.6 & 3.5 & 0.3 & 3.3 & $0.32: 1$ \\
\hline
\end{tabular}



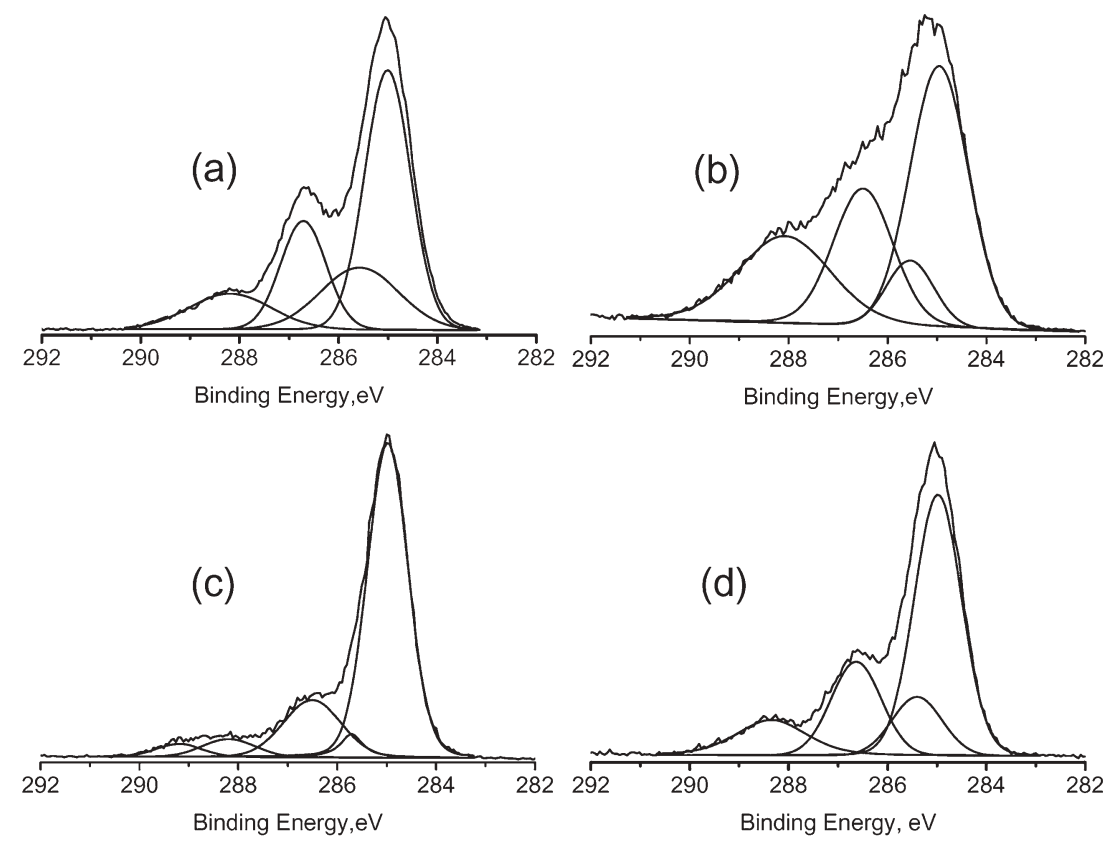

Fig. $1 \mathrm{C}_{1 \mathrm{~s}}$ core level spectra of non treated chitosan (a), plasma treated (b), AA grafted (c) and VSA grafted (d) materials.

Table $2 \mathrm{C}_{1 \mathrm{~s}}$ core level spectra of untreated and modified samples; composition (\%) and binding energy (eV, in parentheses)

\begin{tabular}{|c|c|c|c|c|c|}
\hline Sample & $\mathrm{C}-\mathrm{H}$ & $\mathrm{C}-\mathrm{NH}_{2}$ & $\mathrm{C}-\mathrm{O}$ & $\mathrm{C}=\mathrm{O}$ & $\mathrm{O}=\mathrm{C}-\mathrm{O}$ \\
\hline Chitosan & $48.7(285.00)$ & $19.8(285.57)$ & $20.1(286.71)$ & 11.9 (288.18) & - \\
\hline Plasma $\mathrm{O}_{2}$ & $43.4(284.96)$ & $8.8(285.54)$ & $23.9(286.49)$ & $23.9(288.07)$ & - \\
\hline Grafted AA & 70.4 (284.97) & $3.9(285.71)$ & $17.7(286.50)$ & $4.9(288.19)$ & $3.1(289.20)$ \\
\hline Grafted VSA & 54.7 (284.94) & $12.7(285.41)$ & $20.3(286.63)$ & $12.3(288.34)$ & - \\
\hline
\end{tabular}

A loss in the relative intensity of the hydrocarbon peak was measured after plasma treatment. This was accompanied by an increase in the intensity of oxygen containing bands. After AA grafting a new band appeared in the $\mathrm{C}_{1 \mathrm{~s}}$ high resolution spectra $(289.2 \mathrm{eV})$. This band was assigned to the $\mathrm{O}=\mathrm{C}-\mathrm{O}$ lateral group in the grafted polymer. The absence of the $C-\mathrm{SO}_{3}$ band from the spectra of VSA modified membranes was somewhat unexpected, since the presence of the $S_{2 \text { s }}$ peak in the survey spectrum confirmed that VSA was successfully grafted. The difficulty in resolving the $\mathrm{C}-\mathrm{SO}_{3}$ band arises from the small chemical shift ${ }^{18}$ of the $\mathrm{C}-\mathrm{S}$ band, which is superimposed on the band of the hydrocarbon chemical bonds in chitosan observed at $285 \mathrm{eV}$. Additionally, the relatively small amount of sulfur (see Table 1) and the high intensity of the hydrocarbon band hinders the correct resolution of the bands.

\section{SEM analysis}

Etching processes are unavoidable when polymers are exposed to plasma. Usually, these processes are very dependent on the time and power used and they are limited to the topmost material surface layer. SEM was used to observe eventual morphology changes of the materials' surface. SEM micrographs of the untreated chitosan film revealed a smooth surface without pores, nodes or defects (data not showed). The analysis of the treated materials indicated that none of the modification process, either oxygen plasma treatment or grafting polymerization, affected the surface morphology of the modified membranes.

\section{FTIR analysis}

Fig. 2 shows the FTIR spectra of untreated and modified membranes. In the chitosan spectrum (Fig. 2(a)), the $\mathrm{NH}_{2}$ characteristic absorption band is observed at $1600 \mathrm{~cm}^{-1}$. The bands assigned to the stretching vibration of $\mathrm{C}-\mathrm{O}-\mathrm{C}$ linkages in the saccharide structure (glucosamine rings) appear at 1155 , 1067, 1030 and $894 \mathrm{~cm}^{-1}$. The absorptions at 1324 and $1380 \mathrm{~cm}^{-1}$ reflect the stretching vibration of the $\mathrm{C}-\mathrm{N}$ bond (amide III) and the $\mathrm{C}-\mathrm{H}$ binding modes of the methylene, respectively. Very weak bands at 1420 and $1645 \mathrm{~cm}^{-1}$ corresponding to the $\mathrm{C}-\mathrm{H}$ bond in the methyl and stretching vibrations of the carbonyl group (amide I) reveal the high degree of deacetylation of the chitosan used. ${ }^{19}$

FTIR spectra of the treated materials (Figs. 2(b-d)) show no significant differences compared with the untreated material. This is not surprising since it is well known that at each internal reflection, the penetration depth of the IR radiation beam is around $1-5 \mu \mathrm{m}$ into the polymer membrane. ${ }^{20}$ Moreover, the thickness of the modified layer by plasma treatment is usually confined to few nanometres of the top surface layer and has no effect on the bulk of treated polymers. ${ }^{13}$ On the other hand, the changes indicated by the XPS analysis (more sensitive) reveal that the performed surface 


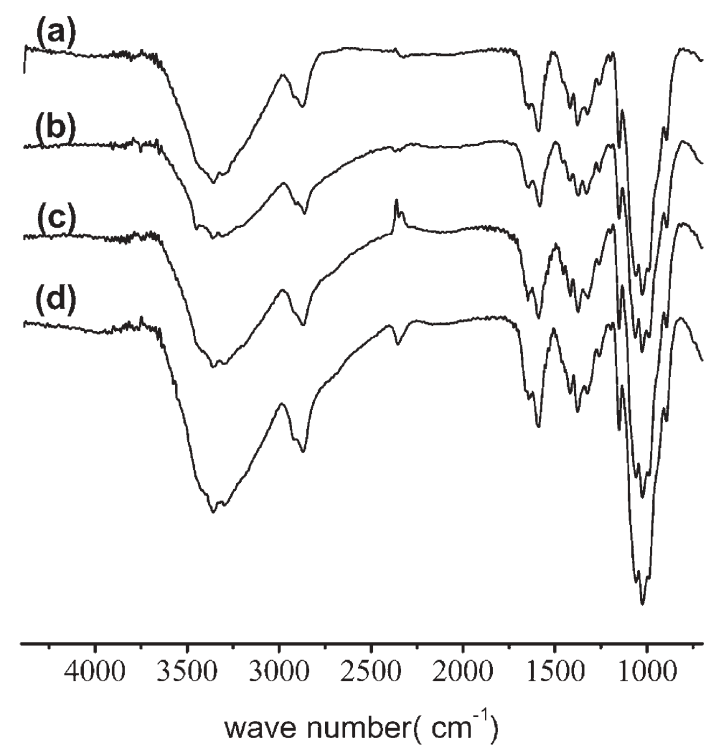

Fig. 2 FTIR-ATR spectra of: untreated chitosan (a) and chitosan modified by $\mathrm{O}_{2}$ plasma (b); AA grafted (c) and VSA grafted (d) materials.

Table 3 Equilibrium contact angle values for untreated and modified samples (air, room temperature)

\begin{tabular}{llll}
\hline Material & $\begin{array}{l}\text { Glycerol } \\
\text { C. } \text { angle }^{\circ}\end{array}$ & $\begin{array}{l}\text { Diiodomethane } \\
\text { C. angle } /{ }^{\circ}\end{array}$ & $\begin{array}{l}\text { Formamide } \\
\text { C. angle }{ }^{\circ}\end{array}$ \\
\hline Chitosan & $83.0 \pm 2.0$ & $52.4 \pm 2.3$ & $68.4 \pm 1.3$ \\
Plasma treated & $73.0 \pm 3.7$ & $49.0 \pm 4.0$ & $50.8 \pm 5.7$ \\
AA grafted & $70.6 \pm 2.7$ & $52.0 \pm 3.2$ & $34.6 \pm 4.7$ \\
VSA grafted & $78.1 \pm 1.1$ & $55.4 \pm 0.7$ & $51.8 \pm 4.6$ \\
\hline
\end{tabular}

modifications have no effect on the bulk properties of the material but only on the very top surface layer.

\section{Contact angle measurements}

The energy of the surface, which is directly related to its wettability, is a useful parameter that has often been strongly correlated with the cell-biomaterial interfacial interactions. Unfortunately, there are no direct methods to measure surface energy or surface tension of solids. However, a number of indirect empirical and semiempirical methods have been developed based on contact angle measurements. Table 3 shows the equilibrium contact angle values of the solvents used for both untreated and modified materials.
The Owens, Wendt, Rabel and Kaelble method has been widely used for the calculation of the total surface energy and its corresponding polar and dispersive components. Generally, the polar component value is used as an estimation of the concentration of the polar groups on the polymer surface. The surface energy values obtained for untreated, plasma treated and grafted samples are shown in Table 4. No apparent significant changes in the total surface energy were observed for any of the studied samples. However, the introduction of additional polar groups by the modification processes was confirmed by an increase in the values of the polar components for all treated samples. Plasma activation itself resulted in a higher value of the polar component $\left(3.5 \mathrm{mN} \mathrm{m}^{-1}\right)$ compared to that calculated for untreated chitosan $\left(1.1 \mathrm{mN} \mathrm{m}^{-1}\right)$. The same effect was observed after VSA grafting $\left(3.0 \mathrm{mN} \mathrm{m}^{-1}\right)$. The most noteworthy difference was observed for AA grafted samples for which a value of $5.9 \mathrm{mN} \mathrm{m}^{-1}$ was calculated.

Usually, the term "polar" is used to designate three classes of compounds, ${ }^{21}$ namely: i) dipolar compounds; ii) hydrogen bonding compounds and iii) compounds that interact as Lewis acids and bases. The Van Oss-Chaudhury-Good theory distinguishes the acid-base $(\mathrm{AB})$ interactions as a component of the surface free energy:

$$
\gamma_{\mathrm{S}}=\gamma_{\mathrm{S}}^{\mathrm{LW}}+\gamma_{\mathrm{S}}^{\mathrm{AB}}
$$

where $\gamma_{\mathrm{S}}^{\mathrm{LW}}$ is the surface energy corresponding to Lifshitz-Van der Waals forces and $\gamma_{\mathrm{S}}^{\mathrm{AB}}$ describes the contribution of the $\mathrm{AB}$ interaction to the surface tension:

$$
\gamma_{\mathrm{S}}^{\mathrm{AB}}=2\left(\gamma_{\mathrm{S}}^{-} \gamma_{\mathrm{S}}^{+}\right)^{1 / 2}
$$

where $\gamma_{\mathrm{S}}^{-}$and $\gamma_{\mathrm{S}}^{+}$represent the ion pair donor (Lewis base) and the ion pair acceptor (Lewis acid) contributions, respectively.

The total surface energy $\left(\gamma_{\mathrm{S}}\right)$ values obtained by the $\mathrm{AB}$ method correlate very well with the values achieved using the OWRK method (see Table 4). Once again, little difference was found between the total surface energy values throughout the surfaces studied. Moreover, the acid component was found to be zero or negligible if compared with the basic component. This means that the modified surfaces present a monopolar character. It is interesting to notice that the tendency observed for the polar component of the surface energy calculated according to the theory of OWRK is similar to that observed for the basic component calculated using the acid-base theory. The non-modified chitosan membranes present lower values $\left(3.0 \mathrm{mN} \mathrm{m}^{-1}\right)$, followed by the $\mathrm{O}_{2}$ plasma modified and the

Table 4 Surface energy ( \pm standard deviation) and its components calculated by the OWRK (glycerol and diiodomethane) and AB (glycerol,

\begin{tabular}{|c|c|c|c|c|c|c|c|}
\hline \multirow[b]{2}{*}{ Material } & \multicolumn{3}{|c|}{ OWRK method } & \multicolumn{4}{|l|}{ AB method } \\
\hline & $\overline{\gamma_{\mathrm{s}} / \mathrm{mN} \mathrm{m}^{-1}}$ & $\gamma_{\mathrm{s}}^{\mathrm{d}} / \mathrm{mN} \mathrm{m}^{-1}$ & $\gamma_{\mathrm{s}}^{\mathrm{p}} / \mathrm{mN} \mathrm{m}^{-1}$ & $\overline{\gamma_{\mathrm{s}} / \mathrm{mN} \mathrm{m}^{-1}}$ & $\gamma_{\mathrm{s}}^{\mathrm{LW}} / \mathrm{mN} \mathrm{m}^{-1}$ & $\gamma_{\mathrm{s}}^{+} / \mathrm{mN} \mathrm{m}^{-1}$ & $\gamma_{\mathrm{s}}^{-} / \mathrm{mN} \mathrm{m}^{-1}$ \\
\hline Chitosan & $32.9 \pm 0.3$ & $31.8 \pm 0.3$ & $1.1 \pm 0.2$ & $32.7 \pm 0.3$ & $32.7 \pm 0.0$ & $0.0 \pm 0.0$ & $3.0 \pm 0.3$ \\
\hline Plasma treated & $35.8 \pm 0.6$ & $32.2 \pm 0.3$ & $3.5 \pm 0.5$ & $35.4 \pm 0.9$ & $35.0 \pm 0.0$ & $0.0 \pm 0.0$ & $9.1 \pm 1.0$ \\
\hline AA grafted & $35.4 \pm 1.0$ & $29.5 \pm 0.4$ & $5.9 \pm 0.9$ & $34.6 \pm 1.5$ & $32.6 \pm 0.0$ & $0.1 \pm 0.1$ & $14.6 \pm 1.6$ \\
\hline VSA grafted & $31.9 \pm 0.5$ & $28.9 \pm 0.3$ & $3.0 \pm 0.5$ & $31.0 \pm 0.1$ & $31.0 \pm 0.1$ & $0.0 \pm 0.0$ & $12.1 \pm 1.0$ \\
\hline
\end{tabular}
formamide and diiodomethane) methods

${ }^{a} \gamma_{\mathrm{s}}=$ surface energy; $\gamma_{\mathrm{s}}^{\mathrm{d}}$ and $\gamma_{\mathrm{s}}^{\mathrm{p}}=$ dispersive and polar components of surface energy calculated by the OWRK method; Lifshitz-Van der Waals $\left(\gamma_{\mathrm{s}}^{\mathrm{LW}}\right)$, acid $\left(\gamma_{\mathrm{s}}^{+}\right)$and basic $\left(\gamma_{\mathrm{s}}^{-}\right)$components of the surface energy calculated by the AB method. 
VSA grafted films (9.1 and $12.1 \mathrm{mN} \mathrm{m}^{-1}$ respectively). Samples grafted with AA present the highest value of the basic component $\left(14.6 \mathrm{mN} \mathrm{m}^{-1}\right)$. We found that this tendency is strongly correlated with cell behaviour, as detailed in the following section.

The water contact angle values were not used in the computation of surface energy, because these values lack physical meaning. If fact, the chitosan membranes absorb water up to $130 \%$ of their own weight. ${ }^{4}$ In this way, the measured contact angle is associated with non-equilibrium events resulting from the swelling of the membranes. This swelling also creates a surface deformation in the samples beneath the liquid water drop. This effect is more pronounced in the modified surfaces in which the sorption events were notably faster, likely due to their increased hydrophilicity. Moreover, when the water contact angle values were tentatively included in the computation of the surface energy using both methods, the resultant correlation coefficients were found to be close to zero (good correlation should give a correlation coefficient close to 1). These initial calculations also presented high $\chi^{2}$ values, revealing that the theories would not describe such a set of experimental data. In this sense, the water contact angle was removed from the calculations.

\section{Cell morphology}

Anchorage-dependent cells (fibroblast, osteoblast or endothelial cells) need to adhere in order to proliferate. Since the materials studied in this work are to be used for bone-guided regeneration, the effect of surface modification was assessed by cells with the osteoblastic phenotype, the principal cell type facing these devices in vivo.

Fig. 3 shows optical micrographs of cells adhered to untreated and modified materials after 3 and 7 days of culture. It can be observed that cells adherent to chitosan surfaces did not show the characteristic morphology of osteoblast-like cells at any of the tested culture times, which may indicate a deficient long-tem cell response. Poor cell attachment on chitosan has been reported ${ }^{5}$ before. The AA surface grafting did not induce any improvement in the cell behaviour; cells presented a round shape and the surface showed reduced cell adhesion. On the other hand, SaOs-2 in contact with plasma treated and VSA grafted materials demonstrate very good adherence to these surfaces. These treatments appear to render chitosan membranes with the appropriate physico-chemical properties for adherence and proliferation of SaOs-2. This hypothesis was confirmed by the observation after 7 days of culture that a significant surface area was covered by a monolayer of cells (Fig. 3). Moreover, cell morphology was positively affected by both treatments. SEM micrographs for 3 days of culture (Fig. 4) showed that cells present the typical morphology for osteoblastic cells with cytoplasm extensions.

In their normal mechanism, cells in contact with a surface will initially attach, adhere and spread. Protein adsorption is a determining step for this first phase and will further control cell morphology, as well as their proliferation capacity. It has been proved ${ }^{22}$ that the type of adsorbed proteins and their orientation are related to the surface properties, especially to

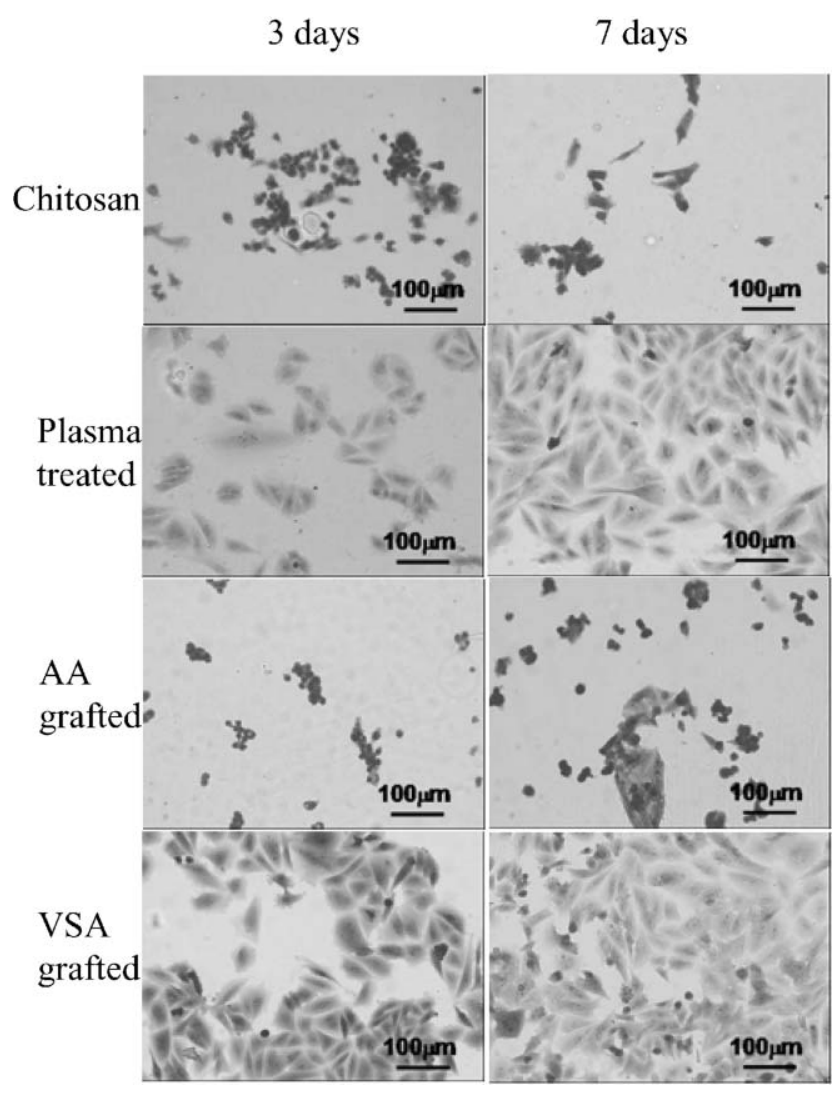

Fig. 3 Optical micrographs of osteoblast-like cells stained with methylene blue cultured for 3 and 7 days.
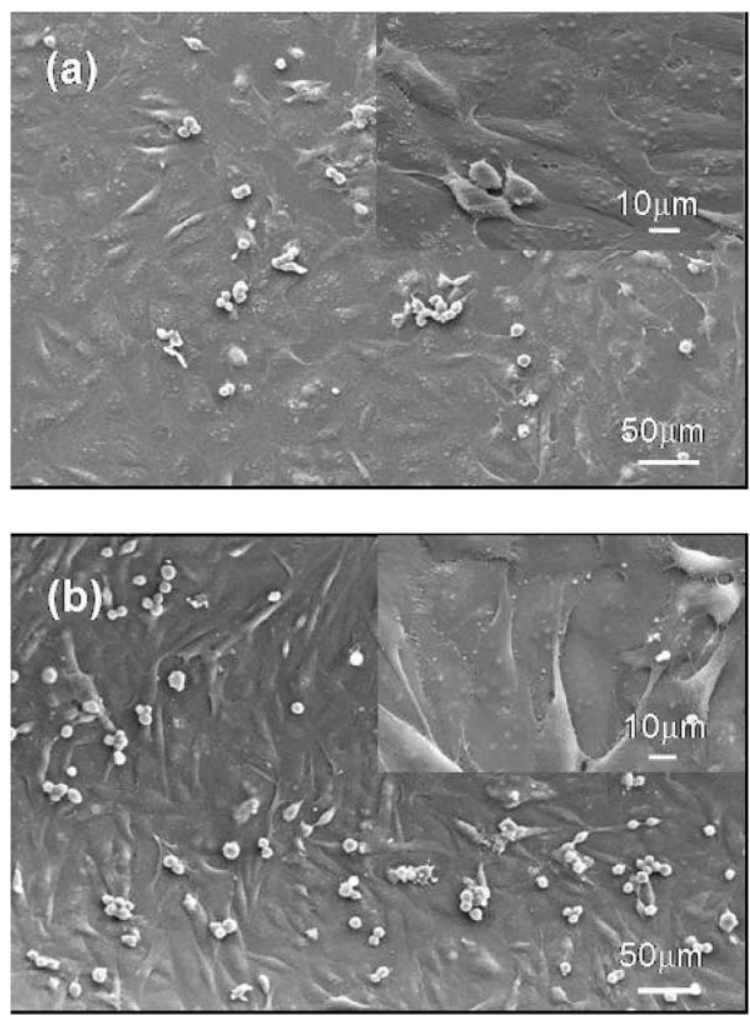

Fig. 4 SEM micrographs showing SaOs-2 cultured for 3 days on the surface of plasma treated (a) and VSA grafted (b) membranes. 
the surface energy. Moreover, it has been reported ${ }^{23}$ that the dispersive and polar components of the surface energy are of key importance for the interfacial interactions. Therefore, an optimal distribution of the two components is required. As can be seen from the contact angle results (Table 4), neither very low polar component (untreated chitosan) nor very high (AA grafted material) were favourable for the correct cell attachment/morphology. On the contrary, the intermediate polar components achieved for plasma treated and VSA grafted samples, influenced the cell behaviour on these surfaces positively.

It has been also reported that Lewis basicity is a key factor in surface biocompatibility. ${ }^{24}$ In the systems studied herein, the surfaces holding moderate basic component values (Table 4) presented improved $\mathrm{SaOs}-2$ behaviour compared to the samples showing both lower and higher values for the Lewis basicity. The similarity between this result and the one already described for the correlation between the surface energy polar component and the cell behaviour is noteworthy.

\section{MTS assay}

The MTS tests were carried out in order to further evaluate cell viability on treated and untreated membranes (Fig. 5). Metabolically active cells are capable of reducing a tetrazolium compound (MTS) into a water soluble formazan product. Non-viable cells rapidly lost their ability to reduce the MTS. Therefore, the production of the coloured formazan products is proportional to the number of viable cells.

Considering the results reported above on the cell morphology, plasma treated and VSA grafted materials were expected to present better cell viability and proliferation than the untreated and AA grafted samples. The MTS results confirm those differences; the optical density measurements indicate that plasma and VSA treatments lead to a higher number of viable cells adhered to the surface of the materials after 1 day of culture compared to untreated or AA grafted chitosan membranes. The observed effect increases with the culture time. Once again, these results supported the hypothesis that plasma and VSA treatment induce a positive effect on osteoblast-like cells.

\section{Conclusions}

A successful surface modification by plasma induced radical polymerization of acrylic and sulfonic polar monomers onto

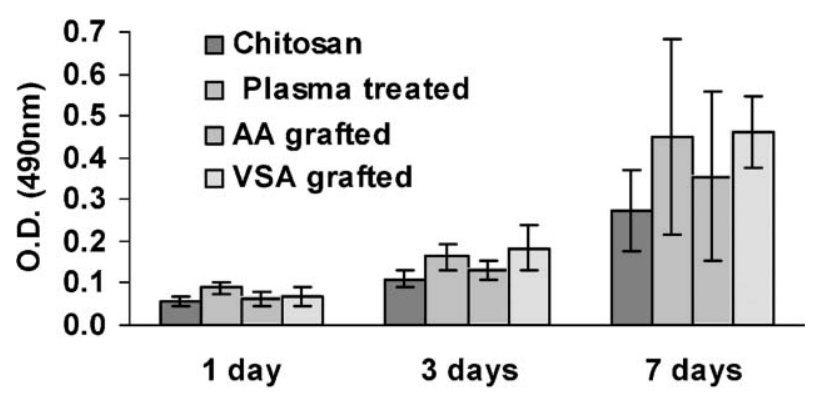

Fig. 5 Viability of SaOs-2 adhered to untreated and modified surfaces after 1,3 and 7 days of culture at $5 \% \mathrm{CO}_{2}$ at $37{ }^{\circ} \mathrm{C}$. solvent cast chitosan membranes was performed. XPS results confirmed the polymer grafting on the membrane surface. FTIR-ATR spectra indicated that this modification took place only on a very thin layer of the surface and the material's bulk properties were not affected. Contact angle measurements showed that the total surface energy does not change significantly after the applied treatments. However, an increased polar component was found for all treated materials. Moreover, the $\mathrm{AB}$ method showed that this increase is generally due to the Lewis base contribution. Cell direct contact tests with SaOs-2 showed that oxygen plasma treatments and VSA grafting substantially improved cell adhesion and proliferation compared with untreated chitosan. These results were correlated with both polar and basic components of the surface energy, showing that materials with intermediate polar and basic components positively affect cell adhesion and proliferation.

\section{Acknowledgements}

The authors acknowledge EU Marie Curie Actions, Alea Jacta EST for providing a PhD Grant to Paula M. López-Pérez, the Portuguese Foundation for Science and Technology (FCT) for providing a postdoctoral grant to I. Pashkuleva (BPD/8491/ 2002). This work was carried out under the scope of the European NoE EXPERTISSUES (NMP3-CT-2004-500283).

\section{References}

1 A. Gallardo, M. R. Aguilar, C. Elvira, C. Peniche and J. San Ramon, in Biodegradable Systems in Tissue Engineering and Regenerative Medicine, ed. R. L. Reis and J. San Roman, CRC Press, Boca Raton, U. S. A., 2005, ch. 10, pp. 145-161.

2 M. N. V. R. Kumar, React. Funct. Polym., 2000, 46, 1-27.

3 E. Khor and L. Y. Lim, Biomaterials, 2003, 24, 2339-2349.

4 R. M. Silva, G. A. Silva, O. P. Coutinho, J. F. Mano and R. L. Reis, J. Mater. Sci.: Mater. Med., 2004, 15, 1105-1112.

5 X. Zhu, K. S. Chian, M. B. E. Chan-Park and S. T. Lee, J. Biomed. Mater. Res., Part A, 2005, 73, 264-274.

6 T. Mori, M. Okumura, M. Matsuura, K. Ueno, S. Tokura, Y. Okamoto, S. Minami and T. Fujinaga, Biomaterials, 1997, 18, 947-951.

7 B. D. Boyan, T. W. Hummert, D. D. Dean and Z. Schwartz, Biomaterials, 1996, 17, 137-146.

8 C. Elvira, F. Yi, M. C. Azevedo, L. Rebouta, A. M. Cunha, J. San Ramon and R. L. Reis, J. Mater. Sci.: Mater. Med., 2003, 14, 187-194.

9 I. Pashkuleva, A. P. Marques, F. Vaz and R. L. Reis, J. Mater. Sci.: Mater. Med., 2005, 16, 81-92.

10 H. X. Sun, L. Zhang, H. Chai and H. L. Chen, Desalination, 2006, 192, 271-279.

11 D. Klee, Z. Ademovic, A. Bosserhoff, H. Hoecker, G. Maziolis and H. J. Erli, Biomaterials, 2003, 24, 3663-3670.

12 I. Pashkuleva and R. L. Reis, in Biodegradable Systems in Tissue Engineering and Regenerative Medicine, ed. R. L. Reis and J. San Roman, CRC Press, Boca Raton, U. S. A., 2005, ch. 23, pp. 429-454.

13 P. K. Chu, J. Y. Chen, L. P. Wang and N. Huang, Mater. Sci. Eng., $R$, 2002, 36, 143-206.

14 A. Hirai, H. Odani and A. Nakajima, Polym. Bull., 1991, 26, 87-94.

15 M. Terbojevich, A. Cosani and R. A. A. Muzzarelli, Carbohydr. Polym., 1996, 29, 63-68.

16 D. K. Owens and R. C. Wendt, J. Appl. Polym. Sci., 1969, 13, 1741.

17 R. L. Reis, S. C. Mendes, A. M. Cunha and M. J. Bevis, Polym. Int., 1997, 43, 347-352. 
18 D. Briggs, in Surface analysis of polymers by XPS and static SIMS, ed. D. R. Clarke, S. Suresh and I. M. Ward, Cambridge University Press, Cambridge, 1998, p. 70.

19 Y. P. Li, L. Liu and Y. E. Fang, Polym. Int., 2003, 52, 285-290.

20 B. D. Ratner, in Biomaterials Science: An Introduction to Materials in Medicine, ed. B. D. Ratner, A. S. Hoffman, F. J. Schoen and J. E. Lemons, Academic Press, San Diego, 1996, ch. 1, pp. 21-35.
21 C. J. Vanoss, M. K. Chaudhury and R. J. Good, Adv. Colloid Interface Sci., 1987, 28, 35-64.

22 L. Y. Liu, S. F. Chen, C. M. Giachelli, B. D. Ratner and S. Y. Jiang, J. Biomed. Mater. Res., Part A, 2005, 74, 23-31.

23 D. H. Kaelble and J. Moacanin, Polymer, 1977, 18, 475-482.

24 E. Ostuni, R. G. Chapman, R. E. Holmlin, S. Takayama and G. M. Whitesides, Langmuir, 2001, 17, 5605-5620.

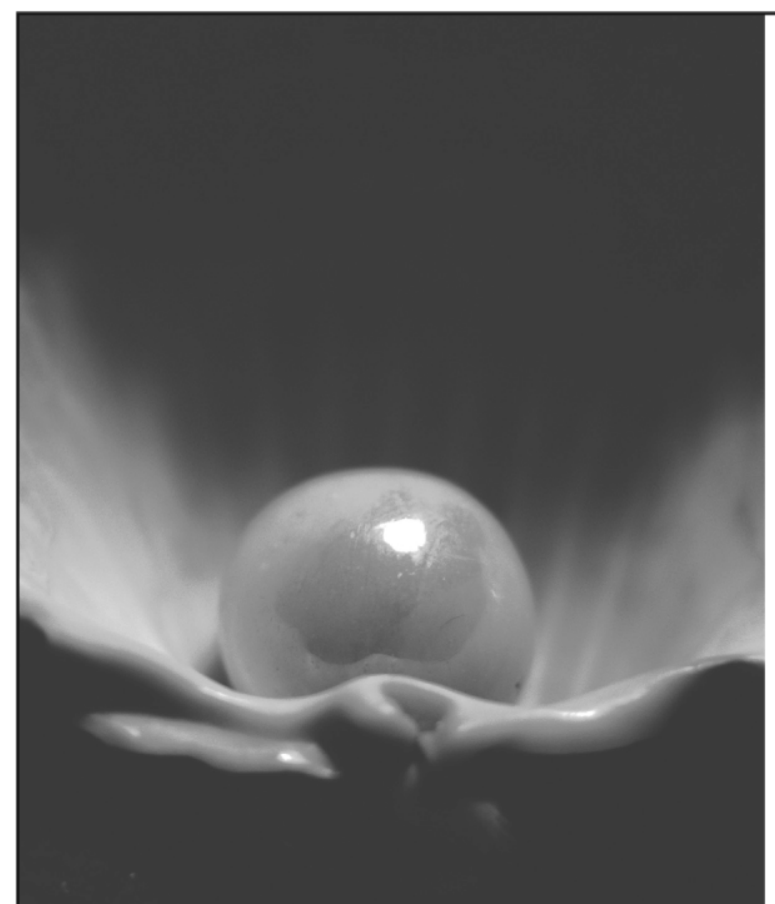

Looking for that SPeCial research paper from applied and technological aspects of the chemical sciences?

TRY this free news service:

\section{Chemical Technology}

- highlights of newsworthy and significant advances in chemical technology from across RSC journals

- free online access

- updated daily

- free access to the original research paper from every online article

- also available as a free print supplement in selected RSC journals.*

*A separately issued print subscription is also available.

Registered Charity Number: 207890 